\title{
Resource allocation during the rereading of scientific texts
}

\author{
KEITH K. MILLIS, SEYMORE SIMON, and NICOLAAS S. TENBROEK \\ Northerm Illinois University, DeKalb, Illinois
}

\begin{abstract}
Two experiments examined how cognitive resources are allocated to comprehension processes across two readings of the same scientific texts. In Experiment 1, readers read and later reread texts describing scientific topics. The results indicated that across readings, readers decreased resources allocated to proposition assembly, increased resources allocated to text-level integration, and expended a similar amount of resources to lexical access. Subjects who reread the texts after a week delay showed a similar pattern, except that they did not show the increase for text-level integration. Experiment 2 revealed a similar pattern of results with a moving window procedure, except that there was a significant decrease in resources allocated to lexical access across exposures. This experiment also indicated that the rereading speedup was greatest at sentence boundaries, suggesting that the prior exposure enabled readers to immediately process each word. Overall, the results are consistent with the claim that readers allocate proportionally more available resources to text-level integration during rereading because proposition assembly, which enables text-level integration, can be completed with fewer resources.
\end{abstract}

Readers typically require more than one reading to understand a difficult text. Students, for example, often read their texts multiple times in hope of increasing their comprehension. Theoretically, multiple readings should facilitate comprehension because there would be more than one opportunity to acquire information from the text. With each reading, the comprehender would be able to further elaborate, repair, verify, and strengthen the existing text representation. Therefore, if a process or operation is not completed during one reading, it might be completed during a subsequent reading. Empirically, processing times have been shown to decrease across repeated exposures (Kolers, 1976; Levy \& Burns, 1990; Rothkopf, 1968), whereas the memory and the comprehension of the material increases (Bromage \& Mayer, 1986; Mayer, 1983; Rothkopf, 1968). Although this body of research indicates that reprocessing facilitates comprehension, the exact nature of how comprehension changes across multiple readings is relatively unknown.

The goal of the present research was to examine the on-line comprehension of scientific texts across two readings of scientific texts. We chose scientific texts because college students normally have difficulty comprehending these types of texts, and therefore would benefit from additional readings. The question of primary

The authors would like to thank Michael Masson, Betty Ann Levy, and two anonymous reviewers for their comments regarding this manuscript. N.S.T. is now at Heartland Community College, Bloomington Normal, IL. Correspondence should be addressed to K. Millis, Department of Psychology, Northern Illinois University, DeKalb, IL 60115 (e-mail:kmillis@niu.edu).

—Accepted by previous editor, Geoffrey R. Loftus interest was, How does the on-line processing of a second reading of a text differ from that of the first reading? In particular, we were interested in whether readers differentially allocate resources to component processes (e.g., lexical access, proposition assembly, text-level integration) across readings. We should stress that relatively little is known about comprehension processes when the reader has previously read the entire text, although there has been some recent work on when readers strategically regress during an initial reading (Goldman \& Saul, 1990). The reason for the lack of empirical studies on rereading and repeated exposures to text is probably that models of discourse comprehension have focused on single readings (e.g., Just \& Carpenter, 1980; van Dijk \& Kintsch, 1983).

We should note, however, that there have been several studies that have examined transfer effects across exposures. Much of this research has been conducted by Levy and her colleagues (Graf \& Levy, 1984; Levy, Barnes, \& Martin, 1993; Levy \& Burns, 1990; Levy et al., 1995; Levy \& Kirsner, 1989; Levy, Masson, \& Zoubek, 1991). A central concern of these researchers has been to identify the types of representations that mediate rereading fluency. Using an approach originally employed by Kolers (1975), Levy and her colleagues have measured transfer effects as a function of the similarity between texts at initial and subsequent exposures. For example, in Levy and Burns, passage reading times were measured after the subjects read the same passages or "scrambled" versions of the passages. Scrambling the paragraphs produced similar reading times as in the same condition, but scrambling the sentences resulted in longer reading times than the same condition (although the times were still faster than the time for the initial reading of the same passage). 
Therefore, the rereading benefit was greatest when passage order information was preserved from one reading to the next. However, there was no transfer when the words of the first text were scrambled, suggesting that abstract word representations do not contribute to rereading fluency. The latter finding has been the subject of some debate among researchers examining word-level transfer effects (Carlson, Alejano, \& Carr, 1991; Carr \& Brown, 1990). Levy's research has also indicated that syntactic representations have a limited impact on rereading fluency because changing the syntactic structure of sentences between exposures does not decrease the amount of transfer (Levy et al., 1993). Overall, Levy's research indicates that perceptual-, lexical-, and message-level information is maintained in the episodic record of a text, and that each make some contribution to reading fluency.

Although this research has contributed to our understanding of reading fluency, questions remain on how specific comprehension processes change across readings. For example, it is possible that the processes involved in reading are executed in exactly the same fashion across readings, but that the activation of representations acquired from an initial reading enables the same processes to be executed much more quickly during reprocessing. A different possibility is that the types of processing or the resources allocated to processes change across readings. It is somewhat difficult to distinguish between these accounts using transfer paradigms alone.

We believe that the assumptions contained in current models of discourse comprehension can be applied to examining changes in comprehension across repeated readings. Next, we discuss several assumptions contained in some existing models of discourse comprehension in order to provide a theoretical basis for studying repeated readings. The models that we have considered have been proposed by Kintsch and van Dijk (1978; van Dijk \& Kintsch, 1983), Just and Carpenter (1980, 1992), Perfetti $(1985,1988)$, and Britton (Britton, Glynn, \& Smith, 1985).

\section{Relevant Assumptions for Rereading}

There are four basic assumptions that, when taken together, provide a fruitful step in understanding comprehension changes across readings. The first assumption is that some of the component processes involved in reading are hierarchically arranged, with the outputs of some processes serving as the inputs to other processes. For example, at least some letters need to be encoded before a word can be recognized. In this fashion, the output of a letter recognition program serves as the input to the lexical access program. The second assumption is that the processes consume differing amounts of cognitive resources from a limited pool. For example, it is commonly assumed that word recognition requires fewer resources than constructing a proposition from the explicit text. The third assumption is that the amount of resources required for the successful execution of a process is partly based on the activation level of its input representation. A process requires fewer resources to the extent that its input representation is currently activated in working memory. This assumption underlies much of the research mentioned earlier on reprocessing and reading fluency. The last assumption is that available resources are allocated to processes on the basis of its position in the hierarchy, especially if the resources are limited or in demand. Resources are allocated to processes lower in the hierarchy before more superordinate processes. If there is a shortage of required resources, the resources normally allocated to the more superordinate processes are scaled back and redistributed to the subordinate processes. For example, MacDonald, Just, and Carpenter (1992) examined reading times for sentences that contained a syntactically ambiguous region (e.g., The farmers warned about the floods had no other crops). They reported that some semantic processing was delayed until the syntactic ambiguity was resolved. The delay occurred for readers who could maintain multiple syntactic representations throughout the ambiguous region (i.e., high-span readers). This finding illustrates the dependency between syntactic and semantic processing; when resources are in short supply (as caused by the maintenance of two different syntactic representations), some semantic processing can be temporarily suspended.

Consider now three processes that are assumed to vary in their required resources and the strength of their output representations: lexical access, propositional assembly, and text-level integration. Lexical access refers to the retrieval of word meanings from a mental lexicon. Propositional assembly refers to the process of constructing propositions from the text and organizing them into the propositional structure of the text (i.e., the text base). Text-level integration, for the purpose of the present paper, is defined as the process of constructing the situation model. The situation model refers to a representation of the referents and events mentioned in the text (van Dijk \& Kintsch, 1983), including the causal connections among the events mentioned in the discourse and inferences based on the reader's world knowledge (Graesser, Singer, \& Trabasso, 1994). Text-level integration also involves the process of determining how the explicit text ideas relate to one another conceptually so that they can be coherently represented in the situation model.

Table 1 summarizes the position in the hierarchy, required resources, and length of output representations for lexical access, proposition assembly, and text-level integration. Of these three, lexical access is the most sub-

Table 1

The Hierarchical Level, Required Resources, and Length of Output Representations for Three Discourse Processes

Process Attributes

\begin{tabular}{llll} 
& \multicolumn{3}{c}{ Process Attributes } \\
\cline { 2 - 3 } \multicolumn{1}{c}{ Process } & $\begin{array}{c}\text { Level in } \\
\text { Hierarchy }\end{array}$ & $\begin{array}{c}\text { Required } \\
\text { Resources }\end{array}$ & $\begin{array}{c}\text { Duration of } \\
\text { Representation }\end{array}$ \\
\hline Lexical access & low & low & short \\
Proposition assembly & medium & medium & medium \\
Text-level integration & high & high & long \\
\hline
\end{tabular}


ordinate because other processes depend on its outputs (Perfetti \& Hogaboam, 1975). That is, lexical access is a prerequisite to constructing a proposition. Lexical access requires very few resources and sometimes is characterized as being automatic (Kintsch \& Mross, 1985; LaBerge \& Samuels, 1974; Swinney, 1979). In addition, its output representation is relatively brief, lasting anywhere from a few seconds to days (Foss, 1982; Jacoby, 1983). Propositional assembly would be "higher" than lexical access in the hierarchy because its input representation is partly based on the output of lexical access. Proposition assembly also requires more resources than lexical access, in part because the temporal nature of language comprehension necessitates that partial products are kept in working memory as the final representation is incrementally constructed (Just \& Carpenter, 1992). There is also evidence that text base representations last longer than word-level representations (Schmalhofer \& Glavanov, 1986). Finally, text-level integration is the most superordinate of the three processes because it requires the output of the other two processes. To perform text-level integration, the reader must have access to some or all of the propositions explicitly stated in the text. Out of the three processes, constructing text-level integration consumes the most resources because the situation model contains causal-based inferences that could span relatively large distances in the explicit text. In addition, the output of text-level integration (i.e., the situation model) lasts longer than the other representations (Schmalhofer \& Glavanov, 1986; van Dijk \& Kintsch, 1983).

We should note that these assumptions are only meant to provide an approximation of the processes that might be implicated across exposures. One important way that these assumptions are limited is that they do not account for complex interactions among the processes, such as top-down processing during an initial reading. They only allow for bottom-up processing because the execution of a process cannot begin unless the inputs from subordinate processes are available. One way that top-down processing is known to occur is when comprehension is guided by activated knowledge structures stored in longterm memory, such as schemas, scripts, and MOPS (Schank \& Abelson, 1977; Sharkey, 1986). These knowledge structures aid comprehension by providing information that might be included in the situation model (e.g., knowledge-based inferences) and about what might be upcoming in the passage. However, we believe that top-down processing during an initial reading should be fairly limited for expository texts. Because readers are typically unfamiliar with the content of expository texts (Black, 1984; Graesser, 1981), they would have a fairly impoverished knowledge base to allow for top-down processing. Therefore, we believe that the above assumptions are justified for expository texts. Of course, top-down processing could occur during reprocessing because the reader would have access to the passage representation acquired from the earlier reading. This would allow the reader to expect upcoming text (Levy \& Burns, 1990 ) and to strategically focus on problematic areas of the text.

The set of four assumptions mentioned previously generates three hypotheses regarding how comprehension might differ across repeated readings of the same text. Specifically, the hypotheses address how readers might differentially allocate their resources to the processes across readings. First, lexical access should consume fewer resources during each subsequent reading of a text. This is based on the assumption that lexical access is relatively automatic for adult readers (Kintsch \& Mross, 1985; Swinney, 1979). Would lexical access require fewer resources during reprocessing? We would expect a decrease to the extent that word-level representations constructed from the first reading are available during the second reading. Research on the word repetition effect and implicit memory suggests that words can have relatively long-lasting representations and that prior exposure to a word can facilitate recognition of that word days later (Jacoby, 1983; Scarborough, Cortese, \& Scarborough, 1977). This word repetition effect is also strongest for low-frequency words (Scarborough et al., 1977) and words appearing in their original context (Masson \& Freedman, 1990). On the basis of these findings, a decrease in resources allocated to lexical access across exposures would be expected because we used expository passages that contained some low-frequency words, and the words were presented in exactly the same context (i.e., the same passages across exposures). On the other hand, some research indicates that the activation of a word's meaning lasts only a few seconds (Foss, 1982). If the activation of a word's meaning is responsible for the word repetition effect, we would expect little, if any, change for lexical access because the delays were much longer than a few seconds (i.e., several minutes and days).

Second, fewer resources should be allocated to proposition assembly during the second reading because the propositions encoded from the first reading should be partially or fully activated during rereading. Consequently, they should be abstracted from the text using fewer resources. The third hypothesis is that text-level integration should be allocated proportionally more resources during rereading because it should consume fewer resources. Text-level integration should be allotted some of the freed-up resources because it is likely that this process will not be completed during the first reading of expository texts (Britton et al., 1985).

The present paper presents two studies that examined how readers allocate their resources to lexical access, proposition assembly, and text-level integration across two readings of the same scientific texts. Subjects in these studies read the experimental passages once, and then read them again after a delay. Subjects in an immediate (delay) condition reread the passages within the same experimental session, whereas subjects in a delay condition reread the passages one week later. We estimated the consumption of resources associated with 
each process by using a multiple regression methodology commonly used in discourse processing research. With this methodology, reading times are predicted from a host of predictor variables (Graesser, Hoffman, \& Clark, 1980; Haberlandt \& Graesser, 1985; Just \& Carpenter, 1980; Millis, Morgan, \& Graesser, 1990; Simon $\&$ Ditrichs, 1988). Reading times were used because they constitute an on-line measure of resource consumption (Aaronson \& Ferres, 1984; Graesser et al., 1980). Typically, the predictors of theoretical interest are related to a process (e.g., proposition assembly). For each predictor, a regression coefficient is computed representing the estimated change in reading time with each unit change in the predictor, while adjusting for shared variance with other predictor variables. The magnitude of the resulting coefficients indicates the amount of resources allocated to the process represented by that predictor.

This methodology has been routinely used to test the impact of particular predictors under different processing conditions (e.g., reading goals, text type, etc.) on reading time. The present studies differ in that we were interested in how the contributions made by each predictor change across readings. Using the same set of predictors, we predicted reading times collected from first and second readings of the same texts. A regression coefficient was computed for Predictor $P$ from the first reading and another was computed for Predictor $P$ from the second reading. The differences in magnitude between these coefficients indicate whether Predictor $P$ had a differential impact on reading times across two readings. Indirectly, changes should reveal whether differing amounts of resources were allocated to the process indicated by Predictor $P$ across readings. For example, if a predictor produced a larger coefficient during the second reading than during the first, readers were allocating more resources to that process during rereading. Alternatively, if a predictor produced a lower coefficient during rereading, fewer resources were allocated to that process. If a predictor had comparable coefficients during both readings, the same amount of resources were allocated to that process.

\section{Predictor Variables}

The predictors of primary theoretical interest were measures of lexical access, proposition assembly, and textlevel integration. Measures of the predictor variables were obtained for each sentence in the experimental passages. As a measure of lexical access, the average natural logarithm of the word frequencies associated with the content words mentioned in a sentence was determined using the Kučera and Francis (1967) norms. Content words included nouns, verbs, adjectives, and adverbs, but not prepositions, connectives, and determiners (Graesser $\&$ Riha, 1984). Word frequency was chosen as a measure of lexical access for three reasons. First, several models of word recognition assume that the lexicon is partly or entirely ordered on the basis of word frequency (Morton, 1969; Taft \& Forster, 1976). Second, lexical access is influenced by word familiarity, which is correlated with word frequency (Seidenberg \& McClelland, 1989). Lastly, word frequency is negatively correlated with measures of lexical access, such as lexical decision latencies (Allen, McNeal, \& Kvak, 1992, but see Balota \& Chumbley, 1984).

In order to measure proposition assembly, the number of propositions and the number of new argument nouns in each sentence were computed. The first measure refers to the number of propositions that the reader would be able to construct from the sentence and attach to the text base at that point in the passage (Kintsch, Kozminsky, Streby, McKoon, \& Keenan, 1975). The number of propositions was determined by parsing each sentence into propositions using the methodology suggested by Bovair and Kieras (1985). The interrater reliability was acceptable $(r=.92)$. New argument nouns were defined by the number of nouns in the sentence that had not appeared earlier in the passage; these are thought to reflect the construction of the text base (Haberlandt \& Graesser, 1985). When a noun is read, the current text base is searched for its referent, and because new nouns often do not have a referent in the existing text base, the text base must be updated to accommodate the new proposition (Kintsch \& van Dijk, 1978). This claim is supported by the finding that reading times increase with the number of new argument nouns (Haberlandt \& Graesser, 1985).

As a measure of the extent to which a reader could perform text-level integration (e.g., linking Sentence $P$ with the other sentences in the text), each sentence was rated in terms of its importance to the passage. Sentence importance ratings have been routinely collected for narrative texts because they are positively correlated with the number of causal connections (Trabasso \& Sperry, 1985). Important sentences also take longer to read than less important sentences (Cirilo \& Foss, 1980) and have a higher likelihood of being included in summaries and recall protocols (Trabasso \& van den Broek, 1985). Importance ratings also correlate with the number of cycles that propositions spend in working memory, according to the Kintsch and van Dijk (1978) model of comprehension. A similar pattern of findings has been reported for expository passages, although the correlations have been somewhat lower (Brown \& Smiley, 1977; Meyer \& McConkie, 1973; Millis, Simon, \& Lucas, 1992; Mills, Diehl, Birkmire, \& Mous, 1993). For the present study, we averaged importance ratings that were gathered from 35 independent subjects who, after reading each passage, rated each sentence on its importance to the overall passage. The ratings were based on a 1 (unimportant) to 7 (very important) Likert-type scale.

In addition, we included other well-known predictors of reading time that could not be easily categorized as belonging to lexical access, proposition assembly, or textlevel integration.Consequently, these variables - sentence imagery, sentence serial position, topic familiarity, and topic interestingness-were placed in an "other" category. Sentence imagery was computed by averaging ratings from the same subjects who supplied the impor- 
tance ratings. The imagery rating for a given sentence was collected immediately after the importance rating, again using a 1 (low imagery) to 7 (high imagery) Likert-type scale. Topic familiarity and interestingness ratings were computed by averaging ratings gathered from an additional 34 subjects who rated each passage using a 7-point Likert scale $(1=$ low familiarity or interest $; 7=$ high familiarity or interest) after reading each passage.

Several predictions were considered. First, lexical access should be allocated the same or fewer resources during the second reading as compared with the first. As noted, fewer resources would be required during reprocessing to the extent that the word-level representations from the first reading are present during the second. Therefore, the regression coefficients for word frequency should be negative and should either stay the same or become less negative across readings. Second, fewer resources should be allocated to proposition assembly during the second reading as compared with the first. This is based on the assumption that some of the propositions constructed from the first reading should be active (to some extent) during the second reading. Therefore, the regression coefficients for the predictors assessing proposition assembly (i.e., number of propositions, number of new argument nouns) should be positive but show a decrease across the readings. Of course, the predicted decrease should occur only if the representation acquired from the first reading is available during rereading. Therefore, the predicted decrease should be larger in the immediate condition than in the delayed condition, assuming that the text base shows a greater decay in the latter condition. Third, more resources should be allocated to text-level integration during the second reading as compared with the first. Because text-level integration relies to some degree on the outputs of proposition assembly, the expected increase associated with textlevel integration should occur to the extent that the text base is active during rereading. The extent that the text base is active would be indicated by the extent to which proposition assembly consumes fewer resources during rereading. Therefore, the coefficients for importance were predicted to increase to the extent that the coefficients for the proposition assembly predictors decreased.

A question arises as to whether top-down processing, if present, would qualify these predictions. As mentioned previously, two types of top-down processing might occur. One is top-down processing engendered from world knowledge (e.g., schemas) about the rhetorical structure of the text and the topics conveyed in the text. Such processing would facilitate comprehension and the generation of knowledge-based inferences. We would expect that the predictor topic familiarity would account for some of the variance due to this type of processing, although it might be limited given the relatively new topics conveyed in expository texts. A second source of top-down processing could arise from the activation of the passage representation from the initial reading.
Consequently, this top-down processing could occur only during reprocessing. The prior passage representation might promote top-down processing in two ways. The first is if the prior representation primes the upcoming text in a relatively passive fashion (Levy \& Burns, 1990). According to this possibility, reading time for a sentence or clause should be reduced to the extent that the sentence or clause was encoded earlier, and therefore be active at the time of rereading. Another possibility is if readers become more strategic in their reading during reprocessing because they are focusing on refining and elaborating the initial passage representation. They would tend to spend more time on some sentences, depending on whether the sentences were accurately represented in the text base and situation models. We think that it is precisely this type of processing that would be partially accounted for by the sentence importance predictor.

We should stress that these predictions are concerned with whether the regression slopes decrease, increase, or stay the same across readings, and not with the magnitude of the regression slopes. We would expect that the (unstandardized) regression slopes should be smaller during the second reading because readers spend less time reading a passage during rereading (Kolers, 1976; Levy \& Burns, 1990; Rothkopf, 1968). However, these predictions are nontrivial because some variables are predicted to show an increase (i.e., text-level integration) or a decrease (i.e., proposition assembly). If comprehension processes were to proceed in the same manner during both readings (albeit faster during the second reading), then all of the regression slopes would decrease to a similar extent across readings. This would occur to the extent that the representation from the first reading passively primes the upcoming text.

\section{EXPERIMENT 1}

\section{Method}

Subjects. Eighty undergraduate psychology students attending Northern Illinois University participated for extra course credit.

Materials. The passages were taken from popular science magazines such as American Scientist and Omni. There were 12 passages altogether, 10 of which subjects read and later reread, 1 that subjects read only during the second session, and 1 practice passage. The passage that subjects read only during the second session ("new" passage) was included to assess the extent to which overall reading time speedup was specific to the passages that were read in the first reading. Each passage described a scientific topic, including recent research findings on that topic. For example, one passage discussed the recent use of caffeine to increase sperm mobility in artificial insemination; another explained the concept of relativity. An example passage is presented in Table 2 . The passages were moderately difficult to understand, being suitable for college freshmen. The mean Flesch Reading Ease scores of the passages was 57.8 , indicating a "fairly difficult" level of reading ease (Flesch, 1948). The length of the passages (excluding the practice and new passages) ranged from 11 to 19 sentences $(M=15)$, and the number of words per sentence ranged from 6 to $43(M=19)$. The new passage had 10 sentences, with an average of 17 words per sentence, and had a Flesch score of 53 . 
Table 2

\section{An Example Passage: Superconductors}

Nature again leaped ahead of theory with the discovery of superconductivity. The new superconductors are so easy to make that they have appeared in high-school science projects. Yet the materials are so difficult to understand and control that no one can manufacture reliable products from them. The excitement began in September, 1986, when two Nobel Prize winners published their finding of a metal-oxide ceramic that was superconducting well above $23 \mathrm{~K}$, the previous record Temperature shot upward as the year wore on. Unlike the supernova, no precise data emerge for the breakthrough with superconductors, although the barrier of $77 \mathrm{~K}$ was widely heralded. Above that temperature, liquid nitrogen can be used as a coolant. This is a great improvement over liquid helium. As one popular comparison puts it, liquid helium is as expensive as scotch and liquid nitrogen is cheaper than beer. Crossing the barrier of $77 \mathrm{~K}$ seemed a sure sign that the superconducting revolution had begun. The raw ingredients in the new superconductors typically include a rare earth, such as yttrium, combined with barium, copper, and oxygen. The crystalline structure of the compound has distortions and defects, and the role of these imperfections seems important but is not well described. Scientists who are tinkering with the formula have no precise theory but instead rely on intuition. The details of processing are also important. The compounds are extremely sensitive to minute variations in treatment. Bulk samples are generally prepared by sintering, which fuses the powdered ingredients without melting. The samples are impure and irregular and so are the experimental results. One expert compares the procedure to baking a cake. No two samples are alike even though the same recipe is followed.

Note--Reprinted with permission of American Scientist, journal of Sigma Xi, The Scientific Research Society. Copyright 1988.

\section{Procedure}

All subjects at the start of the study were informed that they would be reading passages about scientific topics. They were instructed to read them carefully because they would be given a comprehension test at a later time. A test was never administered; the purpose of the instructions was to make subjects attentive to the task (Graesser et al., 1980). The subjects then read each passage on a computer screen, one sentence at a time. All subjects read a practice passage before reading the 10 experimental passages. Subjects controlled the presentation pace of each sentence by pressing an advance key, after which the current sentence was erased and the next sentence appeared. The order of the passages was randomized for each subject. The computer recorded sentence reading time in milliseconds.

After reading all of the passages once, subjects in the immediate condition $(n=40)$ reread each passage. Subjects in the delayed condition $(n=40)$ reread the passages 1 week later. All subjects were informed immediately before the second reading that they were to read the passages once more because the experimenter wanted them to do well on the comprehension test that would follow. The second reading differed from the first only in that there was an additional passage that had not been presented during the first reading (i.e., the new passage). This passage was included to assess the extent to which the speedup associated with the second reading was specific to those passages that had been read previously. The order of the passages during the second reading also followed a random presentation for each subject. Because subjects signed up for an experiment that consisted of two sessions separated by 1 week, all subjects during the first session were led to believe that they needed to return 1 week later, but only subjects in the delayed condition in fact returned.

\section{Results}

For each subject, sentence reading times were winsorized to $2 S D$ s above the subject's mean. This was done separately for the first and second readings. This procedure affected approximately $2 \%$ of the scores.

Overall rereading facilitation. We expected that reading times would be faster during the second reading, but that the facilitation would be greatest for those passages that had been read during the first reading. The mean reading time per word was computed separately for each subject (averaging over passages), and the means for the two delay conditions are shown in Table 3 . On the average, subjects in the immediate condition read each word $128 \mathrm{msec}$ faster during the second reading. A Tukey's test conducted on the immediate group's reading times indicated that the times for second reading were significantly faster than those for both the first reading and the new passage, but there was no statistically significant difference between the latter two. (This and all subsequent Tukey tests were conducted at an alpha of .05.) This finding suggests that the speedup was confined to the passages that had been read previously because there was no difference between the initial reading times and the reading times for the new passage. In the delay condition, subjects also sped up during the second reading. There was some evidence, however, that they sped up on the new passage as well. Tukey tests indicated that the first reading, the second reading, and the new passage all differed significantly from each other. Because subjects read the new passage more slowly than the passages that had been read earlier, subjects were not speeding up indiscriminately across the passages during the second reading. These data support research showing that reading times decrease with additional readings (Graf \& Levy, 1984; Kolers, 1976). Because only a particular passage served as the new passage for all subjects, we cannot generalize the results from this passage to other passages. The new passage was shorter than the average passage ( 11 vs. 15 sentences), but had a comparable readability rating. Therefore, we should posit some caution in interpreting the new passage reading times in this experiment and Experiment 2.

Multiple regression analyses. Potential problems with collinearity and multicollinearity were assessed by examining the bivariate correlations and by assessing the extent to which each predictor variable could be predicted from the others (Knight, 1984). Collinearity and multicollinearity make it difficult to estimate each predictor's unique contribution to the dependent variable. Our criterion for collinearity was stipulated as a correla-

Table 3

Mean Reading Times (Milliseconds per Word) for First and Second Readings

\begin{tabular}{llcccc}
\hline & \multicolumn{5}{c}{ Reading } \\
& & First & Second & Facilitation & New \\
\cline { 3 - 5 } Experiment 1 & Immediate & 458 & 330 & 128 & 437 \\
& Delay & 442 & 330 & 112 & 380 \\
Experiment 2 & Immediate & 485 & 360 & 125 & 462 \\
& Delay & 552 & 405 & 147 & 464 \\
\hline
\end{tabular}


Table 4

The Means and Standard Deviations of the Predictor Variables

\begin{tabular}{|c|c|c|c|c|}
\hline \multirow[b]{3}{*}{ Predictor } & \multicolumn{4}{|c|}{ Experiment } \\
\hline & \multicolumn{2}{|c|}{1} & \multicolumn{2}{|c|}{2} \\
\hline & $M$ & $S D$ & $M$ & $S D$ \\
\hline \multicolumn{5}{|l|}{ Lexical access } \\
\hline Word frequency & 4.28 & 1.09 & 6.68 & 2.95 \\
\hline \multicolumn{5}{|l|}{ Proposition assembly } \\
\hline Propositions & 8.19 & 3.78 & - & \\
\hline New argument nouns & 3.34 & 1.94 & 3.78 & 2.15 \\
\hline \multicolumn{5}{|l|}{ Text-level integration } \\
\hline Importance & 5.13 & .68 & 5.24 & .63 \\
\hline \multicolumn{5}{|l|}{ Other } \\
\hline Serial position & 7.90 & 4.45 & 7.83 & 4.32 \\
\hline Imagery & 4.65 & .74 & 4.66 & .71 \\
\hline Topic familiarity & 3.61 & .82 & 3.66 & .80 \\
\hline Topic interestingness & 4.93 & .90 & 4.95 & .86 \\
\hline End of clause & - & & .03 & .18 \\
\hline End of sentence & - & & .05 & .22 \\
\hline Beginning of line & - & & .10 & .30 \\
\hline End of line & - & & .10 & .30 \\
\hline
\end{tabular}

tion of .6 or higher. The only correlation that exceeded this magnitude was that between the number of words and the number of propositions in a sentence $(r=.82)$. The number of words in a sentence was originally included as a measure of sentence length. We excluded the number of words from the analyses because the number of propositions was theoretically more relevant than the number of words. The resulting predictor variables and their descriptive statistics are shown in Table 4 . The bivariate correlations ranged from -.43 to .50 and the resulting $R^{2}$ s ranged from .10 to .41 . Thus, there was no reason to suspect large collinearity or multicollinearity problems in the analyses.

Three regression analyses were conducted on the sentence reading times using the predictors listed in Table $4 .^{1}$ The first and second analyses predicted sentence reading times collected during the first and second readings, re- spectively. The third analysis predicted difference scores, which were computed by subtracting the second reading time for a sentence from the first reading time for that sentence. We refer to the difference scores as allocation change scores (ACS) because the magnitude of these scores partly reflects changes in resource allocation across readings. If a predictor significantly predicted the $\mathrm{ACS}$, this indicates a significant difference between the slopes obtained from the first and second readings. The predictors were entered simultaneously in each regression equation. There was a total of 145 sentences.

The regression analyses were computed separately for each subject. The statistical significance of each predictor was determined by testing whether its averaged unstandardized regression coefficient differed from zero (Lorch \& Myers, 1990). This procedure uses an appropriate error term that is not used in other procedures, such as using reading times that have been averaged over subjects (Lorch \& Myers, 1990). In addition to testing the unstandardized regression coefficients, we tested whether the averaged standardized regression coefficients (beta weights) differed from zero. Because beta weights are based on standardized scores, they allow comparisons across predictors, subjects, and readings. For the clear majority of comparisons, statistical significance did not depend on whether the unstandardized or standardized coefficients were used; statistical differences between the standardized and unstandardized coefficients will be discussed only for tests of theoretical interest.

The resulting averaged regression coefficients are presented in Table 5. All of the variables significantly predicted sentence reading times on the first and second readings. The majority of the slopes were similar in direction and in magnitude to those from previous studies that have predicted sentence reading times for expository text (Millis et al., 1990; Simon \& Ditrichs, 1988). The one exception is that positive slopes were found for fa-

Table 5

Average Slope Coefficients and Standard Errors for the Predictor Variables Across Readings and Delay Conditions (Experiment 1 )

\begin{tabular}{|c|c|c|c|c|c|c|c|c|c|c|c|c|}
\hline \multirow[b]{4}{*}{ Predictor } & \multicolumn{12}{|c|}{ Rereading Condition } \\
\hline & \multicolumn{6}{|c|}{ Immediate } & \multicolumn{6}{|c|}{ Delayed } \\
\hline & \multicolumn{2}{|c|}{ First } & \multicolumn{2}{|c|}{ Second } & \multicolumn{2}{|c|}{ ACS } & \multicolumn{2}{|c|}{ First } & \multicolumn{2}{|c|}{ Second } & \multicolumn{2}{|c|}{ ACS } \\
\hline & Avg & $S E$ & Avg & $S E$ & Avg & $S E$ & Avg & $S E$ & Avg & $S E$ & Avg & $S E$ \\
\hline \multicolumn{13}{|l|}{ Lexical access } \\
\hline Word frequency & $-349 *$ & 65 & $-265^{*}$ & 65 & -84 & 85 & $-340^{*}$ & 57 & $-228^{*}$ & 32 & -112 & 61 \\
\hline \multicolumn{4}{|l|}{ Proposition assembly } & 23 & $190^{*}$ & & $594 *$ & 32 & $430^{*}$ & & & 27 \\
\hline New argument nouns & $321^{*}$ & 46 & $172^{*}$ & 37 & $149^{*}$ & 48 & $294^{*}$ & 30 & $246^{*}$ & 28 & 48 & 35 \\
\hline \multicolumn{13}{|l|}{ Text-level integration } \\
\hline Importance & $469^{*}$ & 75 & $727^{*}$ & 66 & $-258^{*}$ & 89 & $483 *$ & 98 & $459^{*}$ & 56 & 24 & 114 \\
\hline \multicolumn{13}{|l|}{ Other } \\
\hline Serial position & $56^{*}$ & 13 & $69^{*}$ & 10 & -13 & 11 & $34^{*}$ & 14 & $65^{*}$ & 9 & $-31^{*}$ & 11 \\
\hline Sentence imagery & $-303^{*}$ & 90 & $-428^{*}$ & 61 & 125 & 107 & $-311^{*}$ & 71 & $-219^{*}$ & 54 & -92 & 87 \\
\hline Familiarity & $348^{*}$ & 76 & $213^{*}$ & 72 & 135 & 109 & $272 *$ & 72 & $270^{*}$ & 47 & 2 & 80 \\
\hline Interestingness & $-370^{*}$ & 66 & $-357^{*}$ & 71 & -13 & 91 & $-357^{*}$ & 113 & $-184^{*}$ & 62 & -169 & 109 \\
\hline$R^{2}$ & \multicolumn{2}{|c|}{.66} & \multicolumn{2}{|c|}{.72} & \multicolumn{2}{|c|}{.25} & \multicolumn{2}{|c|}{.69} & \multicolumn{2}{|c|}{.75} & \multicolumn{2}{|c|}{.31} \\
\hline
\end{tabular}

Note-ACS, allocation change score. $R^{2} \mathrm{~s}$ were based on reading times that were averaged over subjects (all $p \mathrm{~s}<.001$ ). $*$ Significant standardized and unstandardized slope coefficients $(p \mathrm{~s}<.05)$. 
miliarity. Some studies have reported negative slopes for readers' familiarity (Graesser et al., 1980; Graesser \& Riha, 1984; Millis et al., 1990).

Tests of the predictions. First, readers were expected to allocate the same or fewer resources to lexical access during the second reading as compared with the first. Although the slopes for word frequency tended to decrease across the readings, the slopes for the ACSs were not significant in the immediate $[t(39)=.98, S E d m=85, p<$ $.40]$ or delayed $[t(39)=1.81, S E d m=61, p<.10]$ conditions.

Second, proposition assembly was expected to consume fewer resources during the second reading because the text base constructed from the first reading would be partially active during rereading. The regression slopes for propositions were consistent with this prediction. The number of propositions significantly predicted the ACSs in the immediate group $[t(39)=7.59, S E d m=24$, $p<.01]$ and in the delayed group $[t(39)=5.92, S E d m=$ $27, p<.01]$. On the average, readers in the immediate and the delayed conditions constructed propositions 190 and $164 \mathrm{msec}$ faster during the second reading. The fact that propositions showed significant decreases in both conditions indicates that the individual propositions were still fairly accessible after 1 week.

The number of new argument nouns in a sentence also significantly predicted ACSs. However, this result depended on the length of the delay. New argument nouns significantly predicted ACSs in the immediate rereading condition $[t(39)=3.08, S E d m=48, p<.01]$, but not in the delayed rereading condition $[t(39)=1.35, S E d m=$ $35, p>.20]$. Because new argument nouns reflect the process of linking incoming propositions to the existing text base, this finding might suggest that some of the interpropositional links in the text base weakened over the week delay and had to be recomputed during the second reading.

Lastly, sentence importance was expected to consume more resources during the second reading if the predictors assessing proposition assembly consumed fewer resources, which they had. The regression slope for sentence importance predicted the ACSs in the expected direction for the immediate rereading condition $[t(39)=$ $2.87, S E d m=89, p<.01$ ]; however, no significant change was found in the delayed rereading condition $[t(39)=.21, S E d m=114, p>.50]$. These results indicate that when the text base representation from the first reading was fairly active during the second reading because of the short delay, subjects could further assess the relative importance of each sentence. However, when the text base was less accessible because of the week delay, subjects were less likely to utilize the importance of each sentence in their processing. This is consistent with the assumption that readers would only be able to perform text-level integration with a fairly intact text base. Although the predictors in the "other" category predicted reading times in the first and second readings, only one (serial position in the delayed condition) significantly predicted the ACS.

\section{Discussion}

The results of the regression equations suggest that readers allocated cognitive resources to component processes differently across readings. Lexical access consumed a similar amount of resources across readings, propositional assembly consumed fewer resources, and text-level integration consumed more resources. This pattern of results can be accounted for by the class of models discussed earlier, which suggest that because of limited resources, readers complete relatively more proposition assembly than text-level integration during a first reading. Consequently, during the second reading, readers are able to allocate more resources to text-level integration. This ordering occurs because text-level integration requires some access to the individual propositions.

Although the 1-week delay manipulation did not have a large impact on the regression coefficients, the observed changes across readings were consistent with this account. The primary difference between the two delay groups occurred for new argument nouns and sentence importance. The slopes for these variables changed significantly across readings in the immediate condition, but not in the delay condition. The findings indicate that the passage representation acquired from the first reading was less accessible during the second reading for subjects in the delayed condition than for subjects in the immediate condition. More importantly, the pattern of the changes supports the assumption of dependency between proposition assembly and text-level integration. Because subjects in the immediate condition had fairly easy access to the ideas during the second reading (as indicated by significant decreases in the slope coefficients for propositions and new argument nouns), these subjects could allocate more resources to text-level integration during the second reading. On the other hand, because the representation acquired from the first reading was less active for subjects in the delay condition (as indicated by smaller ACSs for propositions and a nonsignificant decrease in the slope for new argument nouns), these subjects needed to use more of their resources to reestablish the text base during the second reading.

\section{EXPERIMENT 2}

Subjects in Experiment 2 read the passages using a self-paced, word-by-word presentation. The word-byword methodology enabled us to measure the speedup associated with rereading at various locations within the sentences. According to Just and Carpenter's (1980) "immediacy of interpretation" assumption, readers attempt to interpret each word as soon as it is read, rather than adopting a "wait and see" strategy. However, because some information that is required to complete processing spans several words and clauses, some process- 
ing must be postponed to clause and sentence boundaries. Readers use clause and sentence boundaries to finish partially completed processes, compute inferences, and incorporate the representation into long-term memory (Graesser, Haberlandt, \& Kiozumi, 1987; Just \& Carpenter, 1980). These "wrap-up" processes are indicated by longer gaze durations and word reading times at the end of clauses and sentences (Chang, 1980; Haberlandt \& Graesser, 1985; Just \& Carpenter, 1980).

There are two competing predictions on the effect that a prior reading would have on wrap-up processing. On the one hand, there might be substantially less wrap-up during the second reading because the representation constructed from the first reading would lessen the need to buffer integrative processing. The representation from the first reading would enable readers to immediately process each word during the second reading. According to this prediction, there should be reading time increments at clause and sentence boundaries during the first reading, but the increases should be substantially smaller or absent during the second reading. On the other hand, some of the wrap-up during the first reading might be due to text-level integration that might be more exhaustive during the second reading. According to this view, the amount of wrap-up processing would either increase or remain the same across readings.

\section{Method}

Subjects. Fifty-six undergraduate psychology students attending Northern Illinois University participated for extra course credit.

Procedure. The general procedure was the same as in Experiment 1 except that the passages were presented to the subjects using a self-paced, word-by-word moving window procedure (Just, Carpenter, \& Woolley, 1982). The title of the passage first appeared on the computer screen until the subjects pressed an advance key. When the advance key was pressed, the title was removed and the first word of the first sentence appeared on the left side of the computer screen. With each press of the advance key, the current word was removed from the screen and was replaced by the next word to its right. When a word reached the far right of the screen, the computer began a new line with the next word, starting at the left of the screen. All words were presented on the same vertical axis (which was centered on the screen); there was no "line feed" when a new line began. All words except the current word were invisible to the reader. The time each word remained visible on the screen was recorded in milliseconds.

As in Experiment 1, subjects in the immediate group reread the passages after reading all of the passages once. Subjects in the delay group returned 1 week later and reread the passages at that time. Because the experimental sessions were slightly longer with the word-by-word methodology than with the sentence presentation, 3 subjects in the immediate condition left before they completed the experiment. Overall, a total of 23 subjects in the immediate condition and 30 subjects in the delayed condition completed the full experiment.

The words in the passages were assigned the same values on the predictor variables used in Experiment 1. However, there were some differences because the unit of analysis changed from the sentence (Experiment 1) to the word (Experiment 2). First, all words (including prepositions, connectives, and determiners) were assigned a word frequency score, which was the natural logarithm of its frequency in the Kučera and Francis (1967) norms. Second, the number of propositions in a sentence was excluded from the analyses. This was done for theoretical and empirical reasons. The theoretical reason was that because propositions are incrementally constructed over the course of individual words in a sentence, a predictor that measures the total number of propositions in a sentence would be most meaningful at the end of a sentence, when all of the propositions have been constructed. Because we wanted to predict the reading times for all words in a sentence rather than just at the end of sentence words, number of propositions would not be suitable for the majority of words in the analyses. The empirical reason supported this claim. When we included the number of propositions in the analyses that are reported below, it never significantly predicted word reading times ( $p$ s $>.80$ ).

In order to assess the impact of clause and sentence boundaries, the predictor variable clause boundary was included and indicated whether a word ended a clause, and the predictor sentence boundary indicated whether a word ended a sentence (sentence-final words). We should note that these two variables are related to proposition assembly. Because readers integrate propositions at the end of clauses and sentences (Just \& Carpenter, 1980), these variables should predict reading time to the extent that readers are assembling and integrating propositions at these locations. These two variables were dummy-coded using a 1 to indicate the presence of a clause or sentence boundary, and a zero to indicate its absence.

Lastly, screen variables were included in the set of auxiliary variables to assess the impact of a word's location on the computer screen. The predictor start of line assessed the words that began a line on the computer screen. Similarly, the predictor end of line assessed the words that were the last words on a line. These two variables were dummy-coded in a manner similar to the clause and sentence boundary variables.

\section{Results}

For each subject, word reading times were winsorized to $2 S D$ s above the subject's mean, as in Experiment 1. This procedure affected approximately $2 \%$ of the scores.

Overall rereading facilitation. The mean reading time per word was computed separately for each subject, and the resulting means are shown in Table 3 . The results replicated the pattern of means from Experiment 1. Tukey tests conducted on the immediate condition means indicated that the times for the second reading were faster than those for both the first reading and the new passage, but the latter two means did not significantly differ from each other. Tukey tests on the delayed condition also showed the same pattern found in Experiment 1; all three means differed significantly from one another in the following order: first $>$ new $>$ second.

Multiple regression analyses. As in Experiment 1, three multiple regression analyses were computed on the first and second readings, as well as on the ACSs using each subject's data separately. The resulting averaged regression coefficients are reported in Table 6. The analyses differed from those in Experiment 1 in that the unit was word reading time rather than sentence reading time. Consequently, the magnitudes of the slopes were substantially lower than those from Experiment 1 . In addition, the $R^{2}$ s were lower but comparable to those reported by other researchers who have predicted word-by-word reading time (e.g., Haberlandt \& Graesser, 1985).

Because of the additional predictor variables, we again checked for potential problems with collinearity 
Table 6

Average Slope Coefficients and Standard Errors for the Predictor Variables Across Readings and Delay Conditions (Experiment 2)

\begin{tabular}{|c|c|c|c|c|c|c|c|c|c|c|c|c|}
\hline \multirow[b]{4}{*}{ Predictor } & \multicolumn{12}{|c|}{ Rereading Condition } \\
\hline & \multicolumn{6}{|c|}{ Immediate } & \multicolumn{6}{|c|}{ Delayed } \\
\hline & \multicolumn{2}{|c|}{ First } & \multicolumn{2}{|c|}{ Second } & \multicolumn{2}{|c|}{ ACS } & \multicolumn{2}{|c|}{ First } & \multicolumn{2}{|c|}{ Second } & \multicolumn{2}{|c|}{ ACS } \\
\hline & Avg & $S E$ & Avg & $S E$ & Avg & $S E$ & Avg & $S E$ & Avg & $S E$ & Avg & $S E$ \\
\hline \multicolumn{13}{|l|}{ Lexical access } \\
\hline Word frequency & $-23 * \uparrow$ & 5.6 & $-5^{* \dagger}$ & .7 & $-18 \dagger$ & 5.5 & $-24^{* \dagger}$ & 3.2 & $-8^{* \dagger}$ & .8 & $-16^{*} \uparrow$ & 3.3 \\
\hline New argument nouns & $26^{*}+$ & 9.4 & 1 & 1.7 & $25^{*}$ & 9.5 & $28 * \dagger$ & 4.5 & $8^{*} \dagger$ & 2.0 & $20 * \dagger$ & 4.6 \\
\hline \multicolumn{13}{|l|}{ Text-level integration } \\
\hline Importance & 3 & 3.3 & $10^{* \dagger}$ & 2.4 & $-7^{*}$ & 4.1 & 2 & 2.5 & $4 \dagger$ & 1.8 & -2 & 2.6 \\
\hline \multicolumn{13}{|l|}{ Location } \\
\hline End of clause & $73 * \dagger$ & 35.0 & $14 * \dagger$ & 3.7 & $59^{*}$ & 35.0 & $65^{* \dagger}$ & 11.0 & $25^{*} \dagger$ & 37.0 & $40^{*} \dagger$ & 10.3 \\
\hline End of sentence & $109 * \dagger$ & 55.0 & 11 & 8.9 & $98^{*}$ & 57.0 & $107^{* \dagger} \dagger$ & 22.6 & 5 & 8.5 & $102 * \dagger$ & 24.0 \\
\hline \multicolumn{13}{|l|}{ Other } \\
\hline Serial position & -1 & .5 & $2 * \dagger$ & .4 & $-3 * \dagger$ & 1.0 & -1 & .5 & $1 * \dagger$ & .3 & $-2 * \dagger$ & .5 \\
\hline Sentence imagery & 1 & 3.2 & $-7 *+$ & 2.3 & $8^{*}$ & .4 & -1 & 3.5 & $-10^{*} \dagger$ & 2.5 & 9 & 4.7 \\
\hline Familiarity & $-5^{* \dagger}$ & 2.1 & 1 & 2.0 & $-6^{*}+$ & 1.9 & $-5 \dagger$ & 2.5 & 0 & 1.6 & $-5 \dagger$ & 2.1 \\
\hline Interestingness & $-14 * \dagger$ & 5.3 & $-10^{*} \dagger$ & 2.5 & -4 & 5.1 & $-12^{*} \dagger$ & 3.8 & $-8 \dagger$ & 2.7 & -4 & 4.3 \\
\hline Start of line & $27^{* \dagger}$ & 6.1 & $10^{*} \uparrow$ & 2.3 & $17^{* \dagger}$ & 5.8 & $27^{* \dagger}$ & 3.3 & $12 * \dagger$ & 1.9 & $15 * \dagger$ & 4.0 \\
\hline End of line & 5 & 3.3 & $9^{*}$ & 3.1 & -4 & 4.8 & $7 \dagger$ & 2.4 & $18 * \dagger$ & 3.1 & $-11 * \dagger$ & 4.2 \\
\hline$R^{2}$ & \multicolumn{2}{|c|}{.26} & \multicolumn{2}{|c|}{.13} & \multicolumn{2}{|c|}{.20} & \multicolumn{2}{|c|}{.36} & \multicolumn{2}{|c|}{.18} & \multicolumn{2}{|c|}{.33} \\
\hline
\end{tabular}

Note-ACS, allocation change score. $R^{2} \mathrm{~S}$ were based on reading times that were averaged over subjects (all $p \mathrm{~s}<.001$ ). ${ }^{*}$ Significant standardized slope coefficient $(p<.05)$. 'Significant unstandardized slope coefficient $(p<.05)$.

and multicollinearity. The only correlation that exceeded the .60 criterion occurred between word frequency and the number of letters in the word $(r=-.63)$ that was originally included to serve as a measure of word length. The negative direction of the correlation indicated that longer words had lower word frequencies than shorter words. We excluded the number of letters because word frequency was theoretically more relevant to the present experiment than the number of letters. The resulting bivariate correlations ranged from -.45 to .50 , and the $R^{2} \mathrm{~s}$ ranged from .02 to .44 when each predictor variable was predicted from the other variables. The relatively low magnitude of these values suggested that there was no reason to suspect that collinearity or multicollinearity would pose interpretational difficulties in the analyses.

Tests of the predictions. It was predicted that word frequency would not change or show a decrease across the readings. The slopes for word frequency decreased across readings, predicting the ACSs in the immediate $[t(22)=$ $3.20, S E d m=5.5, p<.05]$ and delayed conditions $[t(29)$ $=4.76, S E d m=3.3, p<.05]$. Proposition assembly was predicted to consume fewer resources during rereading. This prediction was supported by the finding that new argument nouns showed significant decreases from the first to the second readings in the immediate condition $[t(22)=2.71, S E d m=9.5, p<.05]$ and in the delayed condition $[t(29)=4.45, S E d m=4.6, p<.01]$.

Resources allocated to text-level integration across readings were expected to increase across readings because the resources allocated to the subordinate processes (i.e., proposition assembly and lexical access ) had decreased. Therefore, the coefficients for sentence importance should have become more pronounced across readings. Sentence importance significantly predicted the ACSs in the immediate condition on the standardized regression coefficients $[t(22)=2.88, M E d m=$ $.008, p<.01]$. It was significant on the unstandardized coefficients using a one-tailed test $[t(22)=1.70, M E d m=$ $4.1, p<.05]$. Sentence importance did not predict the ACSs in the delayed condition.

Intrasentence position. Where do readers speed up within the sentences during rereading? The regression slopes for end of sentence and end of clause all decreased across readings. The decreases on the unstandardized coefficients were significant in the delayed condition, but they were only marginally significant in the immediate condition $(p s<.10)$. However, all decreases were significant on the standardized coefficients. The magnitude of the slopes indicated that subjects paused longer at sentence boundaries than at clause boundaries during the first reading, but not during the second reading. This pattern of data suggests that endof-sentence integrative processing (i.e., wrap-up) occurred primarily during the first reading. To test the statistical significance of the interaction, the unstandardized coefficients were submitted to an analysis of variance (ANOVA) that included intrasentence location (end of clause vs. end of sentence), reading (first vs. second), and condition (immediate vs. delay) as independent variables. The interaction between intrasentence location and reading was significant $\left[F(1,51)=10.98, M S_{\mathrm{e}}=\right.$ $2,943.07, p<.001]$. No other effects were significant, except for the main effects of reading $[F(1,51)=11.40$, $\left.M S_{\mathrm{e}}=25,827.68, p<.001\right]$ and location $[F(1,51)=$ $\left.3.89, M S_{\mathrm{e}}=2,516.21, p<.06\right]$. Therefore, there was support for the hypothesis that a prior reading has a 
greater facilitation at the end of sentences than at end of clauses. This suggests that the representation gained from the first reading enabled the readers to immediately process each word, which obviated the need for extensive sentence wrap-up processing. In addition, the lack of wrap-up processing is further evidence that readers allocated fewer resources to proposition assembly during rereading because proposition assembly is often completed at sentence boundaries.

\section{Discussion}

The findings from the word-by-word presentation partially replicated the results from Experiment 1 , which used a sentence-by-sentence presentation. The pattern of slopes for propositional assembly and text-level integration showed the same pattern as that in Experiment 1: The slopes for new argument nouns decreased in both the immediate and delayed conditions, and the slope for sentence importance increased in the immediate, but not in the delayed, condition. (We should note that the increase for sentence importance was not as powerful as in Experiment 1 because the increase in Experiment 2 was significant only on the standardized coefficients, whereas both standardized and unstandardized coefficients were significant in Experiment 1.) One difference between Experiment 2 and Experiment 1 was that word frequency showed significant decreases in Experiment 2 but not in Experiment 1 . One possible explanation for this discrepancy between experiments is that the word-by-word presentation used in Experiment 2 placed more emphasis on individual words than the sentence-by-sentence procedure used in Experiment 1. This extra emphasis might have facilitated lexical access during the second reading. This is consistent with the finding that single-word presentations show greater transfer effects when subjects read orally with a focus on the individual words rather than on context (Carlson et al., 1991; Carr \& Brown, 1990).

Readers showed substantially less sentence wrap-up processing during the second reading than in the first. Readers continued to pause at clause and sentence boundaries during the second reading, although the effects were relatively small. Interestingly, the end-of-clause effects were about the same (or slightly larger) than the endof-sentence effects during the second reading. This suggests that what slight buffering subjects performed during the second reading was wrapped up at clausal boundaries. Consequently, the representation acquired from the first reading enabled subjects to process the texts in a way that closely approximated immediate processing.

\section{GENERAL DISCUSSION}

The results of the two experiments indicate that across two readings of the same scientific texts, readers allocate fewer resources to proposition assembly and more resources to text-level integration. These results are consistent with four assumptions found in various models of comprehension, namely that component processes in- volved in reading (1) are hierarchically arranged, (2) compete for a limited amount of resources, (3) are rankordered on resource allocation, and (4) require fewer resources to the extent that their input representations are activated (Britton et al., 1985; Just \& Carpenter, 1992; Kintsch \& van Dijk, 1978; Perfetti, 1985; van Dijk \& Kintsch, 1983). When these assumptions are extended to comprehension across multiple readings, they predict that the successful execution of some component processes during an initial reading would free up resources that could be allocated to other processes during rereading (Millis \& Simon, 1994). Subordinate processes would initially have the highest priority because other processes depend on their outputs. Once these processes are successfully executed, the superordinate processes can be allocated to the available resources.

The present experiments demonstrate that reading time resources shifted toward text-level integration across two readings of the same text. It was expected that lexical access (as measured by word frequency) would show a decrease across readings to the extent that the lexical representations acquired from the first reading were available during the second reading. There was no significant decrease in Experiment 1, but there was in Experiment 2. As noted earlier, the inconsistency was likely due to methodological differences between the experiments. The singleword presentation used in Experiment 2 may have placed more attention on individual words than the sentence presentation used in Experiment 1, and this extra attention may have been the cause of the facilitation found for lexical access during the second reading.

It was expected that fewer resources would be allocated to proposition assembly during the second reading, whereas text-level integration would be allocated more. These predictions were based on the assumptions that proposition assembly is a prerequisite to at least some text-level integration and that text-level integration would be less likely than proposition assembly to be fully completed during the first reading. Both predictions were generally supported by the data. In both experiments, readers decreased allocation of their resources to proposition assembly across readings, as measured by propositions and new argument nouns. Subjects also increased allocation of resources to text-level processing across readings. Subjects consistently read important sentences relatively more slowly during the second reading, especially at the short delay. This suggests that subjects were paying more attention to how the individual sentences related to the text as a whole during the second reading than during the first.

We should note that the results for sentence imagery and serial position are also consistent with the claim that text-level integration increased across readings. Seven out of the eight comparisons involving these variables showed an increase, although they were not statistically significant. There is some reason to believe that these variables are indirectly related to text-level integration. Sentence imagery might be related because situation 
models are often depicted as being image-like (Glenberg, Meyer, \& Lindem, 1987; Morrow, Greenspan, \& Bower, 1987). Serial position might be related because as one progresses through the passage, there would be more text information to which the reader could link the current sentence.

We interpreted the increases in sentence importance (and to a lesser extent, imagery and serial position) across readings as indicating an enhancement of text-level integration during the second reading. Another possibility is that the subjects might have spent additional time rehearsing the more important sentences only during the second reading. Of course, this would not be considered text-level integration. Unfortunately, we do not have independent evidence to distinguish between these accounts. Other forms of evidence could be gathered by off-line (e.g., recall, comprehension tests) or on-line tasks (e.g., think-aloud procedures) that measure the products of comprehension. Although we did not collect such measures, prior research suggests that readers do perform more text integration during a second reading. For example, Bromage and Mayer (1986; Mayer, 1983) reported that the memory for a technical text increased with repeated listenings (see Rothkopf, 1968), and the increase was significantly greater for more important ideas than for less important ideas. Similar results would probably occur for the passages used here. The significance of the present studies is that they extend this prior research by providing on-line evidence that subjects perform more integrative processing during rereading.

One question that arises is whether the present results obtained for scientific texts would generalize to other text genres (e.g., narrative text). Using the same methodology as that in Experiment 1, Millis (1995) examined resource allocation across two readings of a narrative text. His findings were similar to the results reported here: The impact of word frequency did not change across readings, and proposition assembly required fewer resources during the second reading. In contrast to the present findings, he found no difference on sentence importance across readings. It was probably the case that subjects in that study constructed a reasonably good situation model of the narrative with only one reading. Of course, this would not necessarily be the case for all narratives. We believe that the potential for a text to afford elaboration is important in considering whether rereading would be beneficial. If a narrative depicts a complicated story plot in intricate detail using special literary devices (e.g., flashbacks, perspective shifts), then many readers would need a second reading to construct the complete situation model as intended by the author. On the other hand, if a text contains unfamiliar concepts and provides little information for the reader to elaborate upon, then multiple readings would probably not help the reader in constructing the coherent situation model. We should also note that such effects would depend on the literary expertise of the reader. Dixon, Bortolussi, Twilley, and Leung (1993) reported that literary effects, such as story liking and appreciation, increased across readings of a literary text for frequent readers but not for infrequent readers. We believe that literary effects are probably linked to the situation model, genre knowledge, and inferences generated by the reader about the goals of the author.

Although the present research was spawned by assumptions held by current theories of discourse representation, we did not directly test them. For example, we assumed that during the second reading, the amount of resources required by a process would be inversely correlated with the activation level of its input representation. Although this is a rather noncontroversial assumption, we attempted to test it by having an independent group of 40 subjects read 5 randomly selected passages from the 10 passages that were used in the two experiments. One half of the subjects then recalled the passages immediately, whereas the other half recalled the passages 1 week later. For each sentence, immediate and delayed memory scores were computed by averaging over recall proportions that were obtained for each proposition in the sentence. We then predicted the second reading times obtained from Experiment 1 using these memory scores along with the predictors in Table 5. The immediate and delayed memory scores were significant negative predictors of rereading time in both conditions $(p s<.05)$, thereby supporting the assumption that processing times decrease as the availability of the input representation increases (as measured by the memory scores). This is also consistent with the claim that a prior reading contributes to top-down processing in that the prior representation primes the upcoming text.

We should point out that in the latter study, the correlations between recall and ratings of sentence importance were very small (immediate recall, $r=.06$; delayed recall, $r=.15$ ). This indicates that sentence importance and sentence memory made (largely) independent contributions to the reading times obtained during the second reading. That is, the results of the regression analyses indicate that reading times decrease when memory for the content is high, and they increase when the sentence is perceived as being important to the text. Why would there be such a low correlation between recall and sentence importance for expository text? Empirically, importance ratings typically result in higher correlations with recall for narrative text than for expository text (Mills et al., 1993). There are several reasons why the correlations would be higher for narrative text. One is that the narratives that have been used by researchers are relatively simple and scripted. Simple narratives allow subjects to use existing knowledge structures (e.g., schemas, scripts) to determine the causal importance of text events during comprehension and to facilitate recall (R. C. Anderson \& Pichert, 1978). In contrast, readers of expository texts cannot as readily rely on knowledge structures because most readers have impoverished knowledge about the concepts conveyed in expositions (Graesser, 1981). For expository texts, readers must rely on the text's structure and content to ascertain the relative importance of the 
propositions contained in the text. Because this process probably cannot be entirely completed with only one reading (as it might be with narratives), the correlation between recall and sentence importance for expository texts would be expected to be small but increase with additional readings (see, e.g., Mayer, 1983).

We should comment on the reliability of the results across the two experiments, since they used slightly different methodologies. Experiment 1 used a sentence-bysentence presentation, whereas Experiment 2 used a word-by-word presentation. We addressed the issue of comparability by computing sentence reading times from the word reading times in Experiment 2 and then predicting them by the variables used in Experiment 1 . This analysis showed mixed results. For the predictors of propositions, new argument nouns, serial position, and topic familiarity, the resulting coefficients were in the same direction and had the same pattern of significance as in Experiment 1. On the other hand, word frequency and sentence imagery resulted in significant positive slopes, which is highly unusual, especially for word frequency, which should show negative slopes. Interestingness also showed positive slopes, but the slopes were not consistently significant. We cannot explain these unusual findings at the present time, but they are undoubtedly due to different task demands inherent in their respective methodologies (word by word vs. sentence by sentence). For example, the time spent on function words in the word-by-word presentation is probably longer than the corresponding time spent on them in the sentence-bysentence presentation. In addition, a reader cannot regress within a sentence in the word-by-word presentation but can in the sentence-by-sentence presentation. Consequently, there appears to be an inequality between sentence reading times collated from a word moving window procedure versus those taken directly from a sentence-by-sentence procedure. Given that both of these methodologies are commonly used in text research, the specific basis for the differing findings needs to be studied systematically in future research.

The present research contributes to a growing number of studies that have examined repeated exposures to text. It has been known for some time that fewer resources are used during the rereading of text. Several studies have documented that processing times decrease with additional readings of the same text (Kolers, 1976; Levy \& Kirsner, 1989; Rothkopf, 1968). However, the primary source of the rereading facilitation has been under debate for some time. Some researchers have argued that the surface representation is responsible for the facilitation (Kolers, 1976), whereas others have argued that a meaning-based representation acquired from the first reading is the primary cause for the facilitation (Carr, Brown, \& Charalambous, 1989; Graf \& Levy, 1984; Horton, 1985; Levy \& Burns, 1990; Masson \& Sala, 1978; Tardif \& Craik, 1989). Our findings are consistent with both views, namely that readers use both surface- and meaning-based representations during rereading. If one assumes that lexical representations are closely related to surface representations, the results of Experiment 2 indicate that the surface representations facilitate rereading. The meaning-based representation acquired from the first reading also appears to facilitate rereading because we found that readers were consistently faster at assembling propositions during rereading.

The present studies also extend previous research by attempting to account for how resource allocation changes across readings. Previous research has relied mainly on passage reading times as the primary measure of rereading behavior. However, such measures are limited because they do not reveal whether readers speed up equally throughout the passage, or more on some sentences than others. We have shown here that readers show a greater speedup on the less important sentences during rereading. Because previous studies have also varied the conditions under which the materials were presented, such as the typography or orientation of the passage (e.g., Kolers, 1976), preceding results may not indicate processing changes that readers would normally exhibit in more natural settings. We think that one value of the multiple regression approach used here is that it can be applied to naturally occurring text.

We should also note that rereading has been extensively studied in the context of study aids, such as advance organizers and note taking (Haenggi \& Perfetti, 1992). Rereading has usually served as a control for other procedures thought to increase comprehension and memory (T. H. Anderson, 1980). Interestingly, the majority of this literature has shown that rereading is as effective in increasing memory as is note taking, outlining, and summarization (T. H. Anderson, 1980; Haenggi \& Perfetti, 1992; Howe \& Singer, 1975). It is thought that these strategies facilitate memory by providing an external storage for later study. The source of rereading facilitation appears to arise from strengthening the representation from the first reading, and from text-level integration. One benefit of rereading is that it might promote more inferential processing than either note taking and outlining.

It is well accepted that people read to satisfy a number of goals, such as to acquire knowledge and to be entertained (Brewer, 1980). There are other goals that might be addressed by rereading, such as clarifying misconceptions, repairing gaps in the representation, elaborating the text, reexperiencing the text, and verifying and strengthening the content of the reader's passage representation. Rereading is important because some of these processes cannot be easily accomplished with only one reading. Given the significance of rereading in acquiring information from text (T. H. Anderson, 1980; Haenggi \& Perfetti, 1992; Howe \& Singer, 1975), it is important to examine rereading processes in detail so as to better understand the conditions under which both comprehension and memory can be enhanced. 


\section{REFERENCES}

Aaronson, D., \& Ferres, S. (1984). The word-by-word reading paradigm: An experimental and theoretical approach. In D. Kieras \& M. Just (Eds.), New methods in comprehension research (pp. 31-68). Hillsdale, NJ: Erlbaum.

Allen, P. A., McNeal, M., \& KvaK, D. (1992). Perhaps the lexicon is coded as a function of work frequency. Journal of Memory \& Language, 31, 826-844.

Anderson, R. C., \& Pichert, J. W. (1978). Recall of previously unrecallable information following a shift in perspective. Journal of Verbal Learning \& Verbal Behavior, 17, 1-12.

ANDERSON, T. H. (1980). Study strategies and adjunct aids. In R. J. Spiro, B. C. Bruce, \& W. F. Brewer (Eds.), Theoretical issues in comprehension: Perspectives from cognitive psychology, artificial intelligence, linguistics, and education (pp. 483-502). Hillsdale, NJ: Erlbaum.

Balota, D. A., \& Chumbley, J. I. (1984). Are lexical decisions a good measure of lexical access? The role of word frequency in the neglected decision stage. Journal of Experimental Psychology: Human Perception \& Performance, 10, 340-357.

BLACK, J. B. (1984). An exposition on understanding expository text. In B. K. Britton \& J. B. Black (Eds.), Understanding expository text (pp. 249-267). Hillsdale, NJ: Erlbaum.

Bovair, S., \& Kieras, D. E. (1985). A guide to propositional analysis of research on technical prose. In B. K. Britton \& J. B. Black (Eds.), Understanding expository text (pp. 315-362). Hillsdale, NJ: Erlbaum.

BREWER, W. F. (1980). Literary theory, rhetoric, and stylistics: Implications for psychology. In R. J. Spiro, B. C. Brewer, \& W. F. Brewer (Eds.), Theoretical issues in reading comprehension (pp. 221-239). Hillsdale, NJ: Erlbaum.

Britton, B. K., Glynn, S. M., \& Smirh, J. B. (1985). Cognitive demands of processing expository text: A cognitive workbench model. In B. K. Britton \& J. B. Black (Eds.), Understanding expository text (pp. 227-248). Hillsdale, NJ: Erlbaum.

BROMAGE, B. K., \& MAYER, R. E. (1986). Quantitative and qualitative effects of repetition on learning from technical text. Journal of Educational Psychology, 78, 271-278.

Brown, A. L., \& SMILEY, S. S. (1977). Rating the importance of structural units of prose passages: A problem of meta-cognition development. Child Development, 48, 1-8.

Carlson, L. A., Alejano, A. R., \& Carr, T. H. (1991). The level-offocal-attention hypothesis in oral reading: Influence of strategies on the context specificity of lexical repetition effects. Journal of Experimental Psychology: Learning, Memory, \& Cognition, 17, 924931.

CARr, T. H., \& Brown, J. S. (1990). Perceptual abstraction and interactivity in repeated oral reading: Where do things stand? Journal of Experimental Psychology: Learning, Memory, \& Cognition, 16, 731-738.

Carr, T. H., Brown, J. S., \& Charalambous, A. (1989). Repetition and reading: Perceptual encoding mechanisms are very abstract but not very interactive. Journal of Experimental Psychology: Learning, Memory, \& Cognition, 15, 763-779.

Chang, F. R. (1980). Active memory processes in visual sentence comprehension: Clause effects and pronominal reference. Memory \& Cognition, 8, 58-64.

CiriLo, R. K., \& Foss, D. J. (1980). Text structure and reading time for sentences. Journal of Verbal Learning \& Verbal Behavior, 19, 96109.

Dixon, P., Bortolussi, M., Twilley, L. C., \& Leung, A. (1993). Literary processing and interpretation: Towards empirical foundations. Poetics, 22, 5-33.

Flesch, R. (1948). A new readability yardstick. Journal of Applied Psychology, 32, 221-233.

Foss, D. (1982). A discourse on priming. Cognitive Psychology, 14, $590-607$.

Glenberg, A. M., Meyer, M., \& Lindem, K. (1987). Mental models contribute to foregrounding during text comprehension. Journal of Memory \& Language, 26, 69-83.
Goldman, S. R., \& SaUl, E. U. (1990). Flexibility in text processing: A strategy competition model. Learning \& Individual Differences, 2, 181-219.

Graesser, A. C. (1981). Prose comprehension beyond the word. New York: Springer-Verlag.

Graesser, A. C., Haberlandt, K. F., \& Kiozumi, D. (1987). How is reading time influenced by knowledge-based inferences and world knowledge? In B. Britton (Ed.), Executive control processes in reading (pp. 217-251). Hillsdale, NJ: Erlbaum.

Graesser, A. C., Hoffman, N. L., \& Clark, L. F. (1980). Structural components of reading time. Journal of Verbal Learning \& Verbal Behavior, 19, 135-151.

GRAESSER, A. C., \& RiHA, J. R. (1984). An application of multiple regression techniques to sentence reading times. In D. Kieras \& M. A. Just (Eds.), New methods in comprehension research (pp. 183-218). Hillsdale, NJ: Erlbaum.

Graesser, A. C., Singer, M., \& Trabasso, T. (1994). Constructing inferences during narrative text comprehension. Psychological Review, 101, 371-395.

GRAF, P., \& LeVY, B. A. (1984). Reading and remembering: Conceptual and perceptual processing involved in reading rotated passages. Journal of Verbal Learning \& Verbal Behavior, 23, 405-424.

HaberlandT, K. F., \& Graesser, A. C. (1985). Component processes in text comprehension and some of their interactions. Journal of Experimental Psychology: General, 114, 357-374.

Haenggi, D., \& Perfetti, C. A. (1992). Individual differences in reprocessing of text. Journal of Educational Psychology, 84, 182-192.

HORTON, K. D. (1985). The role of semantic information in reading spatially transformed text. Cognitive Psychology, 17, 66-88.

Howe, M. J. A., \& Singer, L. (1975). Presentation variables and students' activities in meaningful learning. British Journal of Educational Psychology, 45, 52-61.

JACOBY, L. L. (1983). Perceptual enhancement: Persistent effects of an experience. Journal of Experimental Psychology: Learning, Memory, \& Cognition, 9, 21-38.

Just, M. A., \& CARPENTER, P. A. (1980). A theory of reading: From eye fixations to comprehension. Psychological Review, 87, 329-354.

Just, M. A., \& CARPENTER, P. A. (1992). A capacity theory of comprehension: Individual differences in working memory. Psychological Review, 99, 122-149.

Just, M. A., Carpenter, P. A., \& Woolley, J. D. (1982). Paradigms and processes in reading comprehension. Journal of Experimental Psychology: General, 111, 228-238.

Kintsch, W., Kozminsky, E., Streby, W. J., McKoon, G., \& Keenan, J. (1975). Comprehension and recall of text as a function of content variables. Journal of Verbal Learning \& Verbal Behavior, 14, 196-214.

KinTSCH, W., \& Mross, E. F. (1985). Context effects in word identification. Journal of Memory \& Language, 24, 336-349.

Kintsch, W., \& van DiJK, T. A. (1978). Toward a model of text comprehension and production. Psychological Review, 85, 363-394.

KNIGHT, G. P. (1984). A survey of some important techniques and issues in multiple regression. In D. Kieras \& M. A. Just (Eds.), New methods in comprehension research (pp. 183-218). Hillsdale, NJ: Erlbaum.

KOLERS, P. A. (1975). Memorial consequences of automatized encoding. Journal of Experimental Psychology: Human Learning \& Memory, 1, 689-701

KOLERS, P. A. (1976). Reading a year later. Journal of Experimental Psychology: Human Learning \& Memory, 2, 554-565.

KUČERA, H., \& FRANCIS, W. (1967). Computational analysis of presentday American English. Providence, RI: Brown University Press.

LABERge, D., \& Samuels, S. J. (1974). Toward a theory of automatic information processing in reading. Cognitive Psychology, 6, 293-323.

LEVy, B. A., BARNES, L., \& MARTIN, L. (1993). Transfer of fluency across repetitions and across texts. Canadian Journal of Experimental Psychology, 47, 401-427.

LeVy, B. A., \& BURNS, K. I. (1990). Reprocessing text: Contributions from conceptually driven processes. Canadian Journal of Psychology, 44, 465-482.

Levy, B. A., Campsall, J., Browne, J., Cooper, D., Waterhouse, C., \& WILson, C. (1995). Reading fluency: Episodic integration across 
texts. Journal of Experimental Psychology: Learning, Memory, \& Cognition, 21, 1169-1185.

LEVy, B. A., \& KIRSNER, K. (1989). Reprocessing text: Indirect measures of word and message level processes. Journal of Experimental Psychology: Learning, Memory, \& Cognition, 15, 407-417.

Levy, B. A., Masson, M. E. J., \& Zoubek, M. A. (1991). Rereading text: Words and their context. Canadian Journal of Psychology, 45, 492-506.

LORCH, R. F., \& MYERS, J. L. (1990). Regression analysis of repeated measures data in cognitive research. Journal of Experimental $P_{\text {sy- }}$ chology: Learning, Memory, \& Cognition, 16, 149-157.

MacDonald, M. C., Just, M. A., \& Carpenter, P. A. (1992). Working memory constraints on the processing of syntactic ambiguity. Cognitive Psychology, 24, 56-98.

Masson, M. E. J., \& Freedman, L. (1990). Fluent identification of repeated words. Journal of Experimental Psychology: Learning, Memory, \& Cognition, 16, 355-373.

MASsON, M. E. J., \& SALA, L. S. (1978). Interactive processes in sentence comprehension and recognition. Cognitive Psychology, 10, 244-270.

MAYER, R. E. (1983). Can you repeat that? Qualitative effects of repetition and advance organizers from science prose. Journal of Educational Psychology, 75, 40-49.

Meyer, B. J. F., \& McConkie, G. W. (1973). What is recalled after hearing a passage? Journal of Educational Psychology, 65, 109-117

MiLLIS, K. K. (1995). Encoding discourse perspective during the reading of a literary text. Poetics, 23, 235-253.

Millis, K. K., Morgan, D., \& Graesser, A. C. (1990). The influence of knowledge-based inferences on the reading time of expository text. In A. C. Graesser \& G. H. Bower (Eds.), The psychology of learning and motivation (Vol. 25, pp. 197-212). New York: Academic Press.

MiLlis, K. K., \& Simon, S. (1994). Rereading scientific texts: Changes in resource allocation. In H. Van Oostendorp \& R. Zwaan (Eds.), Naturalistic text comprehension (pp. 115-133). Norwood, NJ: Ablex.

Miluis, K. [K.], Simon, S., \& LuCas, J. (1992, November). Memory for scientific texts. Paper presented at the annual meeting of the Psychonomic Society, St. Louis.

Mills, C. B., Diehl, V. A., Birkmire, D. P., \& Mous, L. C. (1993). Procedural text: Predictions of importance ratings and recall by models of reading comprehension. Discourse Processes, 16, 279-315.

Morrow, D. G., Greenspan, S. L., \& Bower, G. H. (1987). Accessibility and situation models in narrative comprehension. Journal of Memory \& Language, 26, 165-187.

MORTON, J. (1969). Interaction of information in word recognition. Psychological Review, 76, 165-178.

Perfetti, C. A. (1985). Reading ability. New York: Oxford University Press.

Perfettr, C. A. (1988). Verbal efficiency in reading ability. In M. Daneman, G. E. Mackinnon, \& T. G. Waller (Eds.), Reading research:
Advances in theory and practice (Vol. 6, pp. 109-143). New York: Academic Press.

Perfetti, C. A., \& Hogaboam, T. W. (1975). The relationship between single word decoding and reading comprehension skill. Journal of Educational Psychology, 67, 461-469.

RoTHкоPF, E. Z. (1968). Textual constraint as a function of repeated inspection. Journal of Educational Psychology, 59, 20-25.

Scarborough, D. L., Cortese, C., \& Scarborough, H. S. (1977). Frequency and repetition effects in lexical memory. Journal of Experimental Psychology: Human Perception \& Performance, 3, 1-17.

SCHANK, R. C., \& ABELSON, R. P. (1977). Scripts, plans, goals, and understanding. Hillsdale, NJ: Erlbaum.

Schmalhofer, F., \& Glavanov, D. (1986). Three components of understanding a programmer's manual: Verbatim, propositional, and situational representations. Journal of Memory \& Language, 25, 279-294.

Seidenberg, M. S., \& McClelland, J. L. (1989). A distributed, developmental model of word recognition and naming. Psychological Review, 96, 523-568.

Sharkey, N. E. (1986). A model of knowledge-based expectations in text comprehension. In J. A. Galambos, R. P. Abelson, \& J. B. Black (Eds.), Knowledge structures (pp. 49-70). Hillsdale, NJ: Erlbaum. SimON, S., \& Ditrichs, R. (1988, April). Text processing as a function of test expectancy and test difficulty. Paper presented at the annual meeting of the Midwestern Psychological Association, Chicago.

SWInNey, D. A. (1979). Lexical access during sentence comprehension: (Re)consideration of context effects. Journal of Verbal Learning \& Verbal Behavior, 18, 645-674.

TAFT, M., \& FORSTER, K. I. (1976). Lexical storage and retrieval of polymorphemic and polysyllabic words. Journal of Verbal Learning \& Verbal Behavior, 15, 607-620.

TARDIF, T., \& Craik, F. I. M. (1989). Reading a week later: Perceptual and conceptual factors. Journal of Memory \& Language, 28, 107125.

Trabasso, T., \& Sperry, L. L. (1985). Causal relatedness and importance of story events. Journal of Memory \& Language, 24, 595-611.

Trabasso, T., \& van den Broek, P. (1985). Causal thinking and the representation of narrative events. Journal of Memory \& Language, 24, 595-611.

VAN DIJK, T. A., \& KINTSCH, W. (1983). Strategies of discourse comprehension. New York: Academic Press.

\section{NOTE}

1. Passage variability was accounted for in the regression analyses by the predictors familiarity and interestingness, both of which contained one value per passage.

(Manuscript received August 12, 1996; revision accepted for publication January 11, 1997.) 